\title{
Michelle M. JACOB, Indian pilgrims. Indigenous journeys of activism and healing with Saint Kateri Tekakwitha
}

Tucson, University of Arizona Press, 2016, 184 p.

\section{Carmen Bernand}

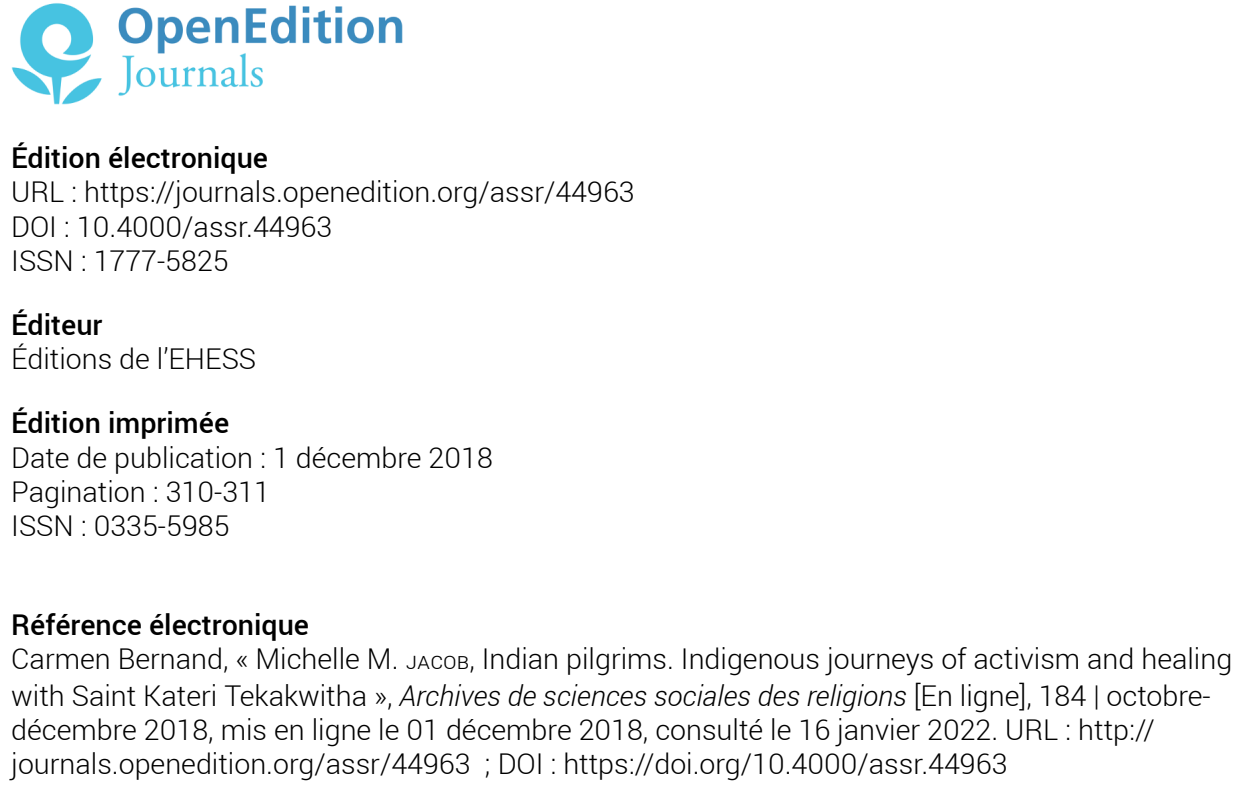

Édition électronique

URL : https://journals.openedition.org/assr/44963

DOI : 10.4000/assr.44963

ISSN : $1777-5825$

Éditeur

Éditions de l'EHESS

Édition imprimée

Date de publication : 1 décembre 2018

Pagination : 310-311

ISSN : 0335-5985

Référence électronique

Carmen Bernand, « Michelle M. ЈАСов, Indian pilgrims. Indigenous journeys of activism and healing with Saint Kateri Tekakwitha », Archives de sciences sociales des religions [En ligne], 184 | octobredécembre 2018, mis en ligne le 01 décembre 2018, consulté le 16 janvier 2022. URL : http:// journals.openedition.org/assr/44963 ; DOI : https://doi.org/10.4000/assr.44963

Ce document a été généré automatiquement le 16 janvier 2022.

(c) Archives de sciences sociales des religions 


\title{
Michelle M. JACOB, Indian pilgrims. Indigenous journeys of activism and healing with Saint Kateri Tekakwitha
}

Tucson, University of Arizona Press, 2016, 184 p.

\author{
Carmen Bernand
}

\section{RÉFÉRENCE}

Michelle M. ЈАСОВ, Indian pilgrims. Indigenous journeys of activism and healing with Saint Kateri Tekakwitha, Tucson, University of Arizona Press, 2016, 184 p.

1 Kateri Tekakwitha, née en 1656 dans la Nouvelle France, algonquine et catholique par sa mère et par son père Agnier-Mohawk (une des six nations iroquoises), est la première autochtone nord-américaine à avoir été canonisée par le Vatican, en l'occurrence par Benoît XVI en 2012, dix ans après la canonisation par Jean-Paul II du contesté Juan Diego, l'Indien nahua devant lequel se présenta Notre-Dame de Guadalupe et grava sur son manteau son image de lumière. Le livre de Michelle Jacob, Amérindienne elle-même et spécialiste universitaire des études concernant les Native American Indians, débute par la cérémonie qui eut lieu à Saint Pierre, réunissant dans la grande basilique un certain nombre de pèlerins américains et canadiens d'origine indigène. L'ouvrage se présente comme une étude ethnographique du culte rendu au xxI ${ }^{e}$ siècle à cette sainte par de nombreuses nations autochtones de l'Amérique du Nord. Kateri avait été béatifiée en 1980 après que le Vatican eut examiné le miracle accompli de son vivant, en l'occurrence la guérison d'un enfant. Elle-même, par ses souffrances, semble avoir été prédestinée à occuper cette place : enfant, elle fut frappée par la variole. L'épidémie la laissa orpheline et défigurée, mais aussi partiellement aveugle, et son nom signifie «celle qui avance à tâtons ». Rappelons que ses parents 
appartenaient à deux nations ennemies, et que les Hurons (auxquels appartenait sa mère) furent massacrés par les Iroquois, épisode à peine esquissé par l'auteur, sans doute parce qu'il s'accorde mal avec sa position idéologique (le lecteur peut se reporter au livre du male white - pour utiliser la terminologie du texte de Jacob -, Richard White, Le Middle Ground. Indiens, Empires et Républiques dans la région des Grands Lacs, 1650-1815, Anacharsis, 2009).

Ce livre est en effet traversé par une idéologie féministe et culturaliste et il faut donc le lire en tant que tel, comme un document militant sur les mouvements religieux ethniques contemporains. À ce titre, il est intéressant. Car les indigènes concernés possèdent une identité commune qui résulte de leur extermination partielle et de leur dépossession à l'époque coloniale (c'est-à-dire le XIX ${ }^{e}$ siècle notamment, précisons-le). Le mouvement religieux et politique rassemblé autour de Kateri se revendique aussi du catholicisme. Il s'appuie sur trois positions fortes: la protection de l'environnement naturel, la création d'une communauté spirituelle et l'empowerment des femmes. Il apporte une vision indigène qui corrige les biais de la littérature coloniale, concernant la sauvagerie indienne et l'action pacifique des missionnaires, et propose une sorte de communauté idéale, combative devant l'attitude actuelle du gouvernement américain (le cas du Canada est moins clair), qui cherche à exploiter les ressources minières que recèlent les territoires des réserves, au détriment de l'environnement. Les nouvelles qui nous parviennent sur cette question donnent raison à ces groupes autochtones. Malheureusement leur combat ne paraît pas mettre en danger ces projets.

3 Le chapitre concernant la Terre-Mère est le plus intéressant et le projet des Amérindiens du Nord rejoint celui des populations métissées de l'Amérique du Sud et $\mathrm{du}$ Mexique, exclues malheureusement par l'auteure. Retenons, parmi d'autres exemples, celui de la défense du Mont Graham (Arizona), une montagne sacrée convoitée par des entreprises minières et occupée par un observatoire d'astrophysique rejeté par les militants apaches (p.125). Des réunions et congrès, universitaires ou autres facilitent les contacts avec les militants de toute l'Amérique du Nord. Ces rassemblements honorent les traditions culturelles indigènes qui s'intègrent aux valeurs catholiques. Il s'agit d'une «inculturation» qui a ses racines ailleurs, dans l'énorme partie du continent américain ignorée par le Nord. Du point de vue féministe, Kateri, par son appartenance (patrilinéaire) à la nations iroquoise, incarne a contrario, puisque sa courte existence a été pénible, le pouvoir matriarcal typique de l'organisation sociale de ces groupes. Ici «matriarcal» est tout de même pris au premier degré et il n'est pas question de discuter le concept. Enfin, la position des groupes par rapport à l'Église ou à la chrétienté en général est ambiguë, et aurait mérité une analyse plus approfondie. Le livre se termine par la description d'un rituel nouveau, les Water Walkers, originaire de la région des Grands Lacs, ici dans sa version universitaire californienne, dans une région affectée cruellement par la sécheresse et les incendies.

Cet idéal de retour aux sources communautaires et aux traditions donne une visibilité aux Amérindiens. Il est significatif que ceux-ci (dans une version idéalisée forgée par la littérature et le cinéma) occupent une place de choix à présent, auprès de courants nationalistes européens surgis en Allemagne, Hongrie, Italie du Nord, comme nous l'apprend un long article publié dans les « Dossiers » du Monde, le samedi 21 juillet 2018. C'est dire l'ambiguïé de ces mouvements et la nécessité d'un regard critique dépourvu de doxa langagière. 